\title{
Low bcl-2 expression and increased spontaneous apoptosis in T-lymphocytes from newly-diagnosed IDDM patients
}

\author{
C. Giordano, G. Stassi, M. Todaro, R. De Maria, P. Richiusa, A. Scorsone, M. Giordano, A. Galluzzo \\ Laboratory of Immunology, Endocrinology Section, Institute of Clinica Medica, University of Palermo, Italy
}

\begin{abstract}
Summary The bcl-2 gene product has been shown to regulate apoptotic cell death, and its dysregulation has been shown to induce several abnormalities in the immune system. No data exist regarding bcl-2 expression in autoimmune diseases, such as human insulin-dependent diabetes mellitus (IDDM). We investigated bcl-2 protein expression by testing $\mathrm{T}$ lymphocytes from 15 newly-diagnosed ( $<3$ weeks) IDDM patients in comparison to 10 age-matched control subjects. The expression of bcl- 2 on $\mathrm{CD}^{+}$ lymphocyte subsets was investigated after membrane permeabilization by two- or three-colour immunofluorescence. When the percentage and mean fluorescence intensity (MFI) of bcl- $2^{+} / \mathrm{CD} 3^{+}$cells from normal individuals and patients were compared, we found that bcl-2 expression within the $\mathrm{CD}^{+}$and $\mathrm{CD}^{+} \mathrm{CD}^{+} 5 \mathrm{R0}^{+}$T-cell populations was reduced significantly in IDDM patients $(46.8 \pm 15.4$ vs $79.6 \pm 11.7 ; 25.7 \pm 3.8$ vs $47.15 \pm 5.7$, respectively;
\end{abstract}

$p<0.001)$. To establish whether low bcl-2 expression in $\mathrm{T}$ cells from newly-diagnosed patients reflects their susceptibility to death by an apoptotic process, we also evaluated DNA staining with propidium iodide in $\mathrm{CD} 3^{+}$lymphocyte suspension after a (24-72 h) culture period (spontaneous apoptosis). We found that IDDM patients have higher levels of spontaneous apoptosis (mean \pm SEM: $24 \mathrm{~h}=4.6 \pm 0.8 ; 48$ $\mathrm{h}=9.9 \pm 1 ; 72 \mathrm{~h}=12.8 \pm 1.1)$ than control subjects $(24 \mathrm{~h}=1.8 \pm 0.4 ; \quad 48 \mathrm{~h}=4.6 \pm 0.4 ; \quad 72 \mathrm{~h}=5.7 \pm 0.3 ;$ $p<0.02-0.001$ ). Our study suggests that recent onset IDDM is characterised by reduced bcl- 2 expression, which in turn may be associated with the increased spontaneous apoptosis we observed. [Diabetologia (1995) 38: 953-958]

Key words $\mathrm{Bcl}-2$, apoptosis, $\mathrm{T}$ cells, flow cytometry, cell-mediated immunity in insulin-dependent diabetes mellitus.
Apoptosis has been reported to be an important mechanism of cell death and cell self-destruction [1]. Unlike cell necrosis, apoptosis is associated with cytoplasm and nucleus condensation, nuclear frag-

Received: 28 November 1994 and in revised form: 10 February 1995

Corresponding author: Dr. C. Giordano, Laboratory of Immunology, Endocrinology Section, Institute of Clinica Medica, Piazza delle Cliniche 2, I-90127 Palermo, Italy

Abbreviations: $\mathrm{MFI}$, Mean fluorescence intensity; mAb, monoclonal antibody; PMA, phorbol myristate; PHA, phytoemagglutinin; Con A, concanavalin-A; PKC, protein kinase $\mathrm{C}$; ICA, islet cell autoantibody; IAA, insulin autoantibody; PE, phycoerythrin; PI, propidium iodide; FSC, forward scatter; SSC, side scatter; PBMC, peripheral blood mononuclear cells. mentation, formation of apoptotic bodies and reduced DNA stainability [2]. Recent studies on clonal deletion have shown that autoreactive $\mathrm{T}$ cells in the thymus are eliminated by an apoptotic process, and that a similar mechanism is also active in peripheral lymphoid organs to maintain self-tolerance and down-regulate an excessive immune response $[1,3-4]$.

Apoptosis is modulated by several inducer or suppressor molecules [3]. Among these regulatory molecules, the protein product of the proto-oncogene bcl2 inhibits apoptosis, preventing several of its stages including blebbing, volume contraction, and endonuclease DNA cleavage $[1,5,6]$. A recent study in transgenic mice overexpressing bcl-2 in the thymus has shown that thymocytes from these animals be- 
come resistant to apoptosis induced by various stimuli such as anti-CD3 monoclonal antibody (mAb), glucocorticoids, phorbol myristate (PMA) or radiation [7]. Besides its apoptosis suppressor activity, bcl2 also differs from other proto-oncogene products in its intracellular localization (mitochondria, endoplasmic reticula, nuclear membranes) [6].

Insulin-dependent diabetes mellitus (IDDM) is a T-cell-mediated autoimmune disease [8,9]. Our in vitro studies in peripheral $\mathrm{T}$ cells isolated from patients with recent-onset IDDM and pre-diabetic subjects have suggested that the disease may also be characterised by a defect in T-cell activation. We have recently reported deficient T-cell blastogenesis after phytoemagglutinin (PHA) or concanavalin-A (Con A) stimulation [10], decreased interleukin-2 production [11], and a reduction in anti-CD3-induced proliferation with marked impairment of protein kinase $\mathrm{C}$ (PKC) translocation [12].

Despite the extreme dilution of islet-specific autoreactive T cells in the peripheral blood, several recent studies have shown sustained T-cell reactivity against pancreatic islet cell antigens such as glutamic acid decarboxylase, both in man [13] and nonobese diabetic mice $[14,15]$. Other reports have shown reactivity against an as yet unidentified granule protein [16] and a $65 \mathrm{kDa}$ heat shock protein [17]. More recently, islet-specific T cells have been isolated from the pancreases of two children who had died at diabetes onset because of ketoacidotic complications [18].

These findings are in apparent contrast with the Tcell hyporesponsiveness we have observed in our studies. Besides the dilution and the consequent poor representation of islet-specific $T$ cells in the periphery, other factors may be responsible for this apparent paradox. One potential explanation is that islet-specific (antigen-primed) peripheral $T$ cells, being chronically-activated cells, cause increased deletion through spontaneous apoptosis. To test this hypothesis, we directly evaluated spontaneous apoptosis and investigated its regulation by measuring bcl-2 expression in CD3-positive cells and in memory CD4-positive lymphocytes $\left(\mathrm{CD} 45 \mathrm{R}^{+}\right)$in patients who had recently developed IDDM in order to show an association with activation of $\mathrm{T}$ cells in the periphery.

\section{Subjects and methods}

Subjects. Through our 14-year family study at the University of Palermo we identified 350 patients and 18 first-degree relatives at increased risk of IDDM because of their positivity for islet cell (ICA) and/or insulin (IAA) autoantibodies.

For this study we randomly selected: a) 15 patients ( 6 males and 9 females) with IDDM with duration of symptoms related to the disease of less than 4 weeks (mean age $18 \pm 4.3$ years); b) 5 patients ( 2 males and 3 females) with long-standing IDDM (48-60 months), mean age $22.9 \pm 2.4$ years; c) 15 non-
Table 1. Baseline characteristics of subjects before entering the study

\begin{tabular}{lll}
\hline & $\begin{array}{l}\text { Newly-diagnosed } \\
\text { IDDM patients }\end{array}$ & Control subjects \\
\hline$n$ & 15 & 10 \\
Male/Female & $6 / 9$ & $5 / 5$ \\
Age (years) & $18 \pm 4.3$ & $22 \pm 3.6$ \\
Time since diagnosis & $5.4 \pm 4.5$ (weeks) & - \\
$\mathrm{HbA}_{1 \mathrm{l}}(\%)$ & $9.2 \pm 2.8$ & $4.4 \pm 2.3$ \\
$\begin{array}{l}\text { Daily glycaemia } \\
\left(\mathrm{mmol}^{\prime}\right)\end{array}$ & $7.8 \pm 1.03$ & - \\
$\mathrm{ICA}^{+}(\%)$ & 87 & 0 \\
\hline
\end{tabular}

diabetic subjects with no family history of diabetes (6 males and 9 females), (mean age $22 \pm 3.6$ years) were studied as control subjects.

Patients were classified according to the criteria of the National Diabetes Data Group [19-20]. All patients were treated after diagnosis with human insulin, usually a combination of short- and intermediate-acting, 3 or 4 times daily. Glycaemic values, fasting and postprandial, were determined by strips and were read by reflectance method during the $24 \mathrm{~h}$ before the study. Glycated haemoglobin $\left(\mathrm{HbA}_{1 \mathrm{c}}\right)$ was determined with an autoanalyzer (Daichi, Kagaku, Kyoto, Japan) on the day of blood sampling (normal range in our cohort of normal subjects $5.5 \pm 1.2 \%$ ) (Table 1 ).

Cells. Peripheral blood mononuclear cells (PBMC) were isolated by Ficoll-Hypaque density gradient centrifugation from heparinized blood of IDDM patients and age- and sex-matched healthy blood donors (Table 1). Cells were washed 3 times in RPMI-1640 (Flow Laboratories, Irvine, UK) and resuspended in RPMI-1640 supplemented with $10 \%$ fetal calf serum (Gibco, Life Tecnologies, Paisley, UK), antibiotics and Lglutamine. This will be referred to as complete medium. For T-cell purification, we used a two-step procedure. The majority of monocytes were removed from PBMC by plastic adherence. Non-adherent cells were then harvested and further enriched in T- or B-cells by negative immunomagnetic selection using CD15 plus CD3 and CD15 plus CD19 specific monoclonal antibodies ( $\mathrm{mAb}$ ), respectively, and goat-anti-mouse-labelled magnetic microspheres (Dynal, Oslo, Norway), as previously described [12]. This procedure resulted in high purification of CD3 positive ( $>98 \%$ ) and CD3 negative ( $>94 \%$ ), as measured by flow cytometry analysis.

Fixation protocol. For the immunodetection of the intracellular bcl-2 protein we used the paraformaldehyde/triton proto$\mathrm{col}$, resuspending the cell pellet in $2 \mathrm{ml}$ of $2 \%$ paraformaldehyde (freshly prepared). After $10 \mathrm{~min}$ on ice, $100 \mu \mathrm{l}$ of $1 \%$ Triton X100 (Sigma, St Louis, Mo., USA) (final concentration $0.05 \%$ ) was added, and $10 \mathrm{~min}$ later the cells were washed twice in cold phosphate buffered saline [21].

Immunofluorescence staining and flow cytometry analysis. The T-cell specific monoclonal antibodies (mAb) Leu 4 (IgG1 isotype; CD3) and Leu 12 (IgG1 isotype; CD19) (Becton Dickinson, San Josè, CA, USA) were used to identify $\mathrm{CD} 3$ positive and $\mathrm{CD} 19$ positive cells. The anti-bcl-2 $\mathrm{mAb}$ ( $\mathrm{IgG}_{1}$ isotype Dako, Glostrup, Denmark) was used to evaluate the intracellular content for bcl-2 and other surface antigens by double-colour indirect immunofluorescence staining and FACS analysis. As a negative control for immunofluorescence, isotype-mat- 
ched $\mathrm{mAb}\left(\mathrm{IgG}_{1}\right)$ was employed. The fixed cells were incubated with saturating concentrations of the anti-bcl-2 mAb. After $30 \mathrm{~min}$ on ice, the cells were washed 3 times in complete medium and incubated again (30 min on ice) with isotype-specific, Phycoerythrin (PE) goat anti-mouse antibody $(2 \mu \mathrm{g} / \mathrm{ml})$ (Dako). After two more washes, the cells were incubated for $10 \mathrm{~min}$ with $2 \mu \mathrm{g} / \mathrm{ml}$ mouse IgG (Fluka,Ulm, Germany) to saturate binding sites. Finally Leu 12 or Leu 4 (FITC) was added for another $30 \mathrm{~min}$ on ice. After two washes in complete medium, cells were analysed by flow cytometry using a FACScan Becton Dickinson. For the analysis of bcl-2 expression in CD45R0 ${ }^{+}$memory $\mathrm{CD}^{+}{ }^{+} \mathrm{T}$-lymphocytes, three-colour immunofluorescence staining was used. The antibody combinations were fluorescein isothiocyanate anti-bcl-2 (Dako), phycoerythrin (PE) anti-CD45R0 (Dako), and Tri-colour anti-CD4 (Caltag Laboratories, San Francisco, CA, USA).

Spontaneous apoptosis. The method employed was essentially that described by Nicoletti et al. [22]. At 24, 48 and $72 \mathrm{~h}$, the $\mathrm{CD}^{+}$cells were centrifuged at $200 \times \mathrm{g}$ for $10 \mathrm{~min}$, washed, and processed. The centrifuged cell pellet was gently resuspended in $1 \mathrm{ml}$ hypotonic fluorochrome solution (Propidium iodide (PI) $50 \mu \mathrm{g} / \mathrm{ml}$ in $0.1 \%$ sodium citrate plus $0.1 \%$ Triton $\mathrm{X}-100$, Sigma), in $12 \times 75$ polypropylene tubes (Becton Dickinson). The tubes were placed in the dark at $4^{\circ} \mathrm{C}$ overnight before the flow cytometry analysis. This procedure gave very low coefficients of variation of DNA peaks and good discrimination of subdiploid and diploid cells and was used in the whole study.

The PI fluorescence of individual nuclei was measured using a FACScan flow cytometer. The forward scatter (FSC) and side scatter (SSC) of particles were simultaneously measured. Cell debris were excluded from analysis by appropriately raising the SSC threshold. The correct threshold value was selected according to Nicoletti's method [22]. The latter made it possible to distinguish apoptotic cell nuclei from debris by the high SSC value due to condensation of nuclear chromatin, which emitted fluorescence in channels 10-250. All measurements were made with the same instrument settings and at least $10^{4}$ cells were analysed.

\section{Statistical analysis}

The Student's $t$-test and the Student-Neuman-Keuls test (after variance analysis) were used for statistical calculations.

\section{Results}

Newly-diagnosed IDDM T cells express low levels of bcl-2. Quantification of bcl-2 on lymphocyte subsets was achieved by two-colour immunofluorescence staining for bcl-2 (PE) and either the B-or T-cell markers (FITC). The results (Table 2) showed that $55.2 \pm 5.6 \%$ of blood $\mathrm{B}^{+}$cells and $66.6 \pm 4.2$ of $\mathrm{CD}^{+}$cells were bcl-2 ${ }^{+}$. Whereas cases analysed in the two groups expressed similar percentages of bcl2 , differences in the intensity of fluorescence were noticed. In particular, $\mathrm{CD}^{+}$cells isolated from 15 normal individuals and analysed for bcl-2 expression revealed that the majority (mean $79.6 \pm 11.7$ ) expressed bcl-2. The staining intensity was slightly high-
Table 2. Anti-bcl-2 reactivity with lymphocytes from control subjects and newly-diagnosed IDDM patients

\begin{tabular}{lllc}
\hline & & \multicolumn{2}{l}{ Bcl-2 } \\
\cline { 3 - 4 } Cell & Subjects & $\%$ & MFI \\
\hline CD19 $^{+}$ & Control subjects & $55.2 \pm 5.6$ & $82 \pm 9.8$ \\
& Newly-diagnosed & $56.6 \pm 4.2$ & $79.1 \pm 10.5$ \\
& IDDM patients & & \\
$\mathrm{CD}^{+}$ & Control subjects & $66.6 \pm 4.0$ & $79.6 \pm 11.7$ \\
& Newly-diagnosed & $75.2 \pm 7.9$ & $46.8 \pm 15.4$ \\
& IDDM patients & & \\
\hline
\end{tabular}

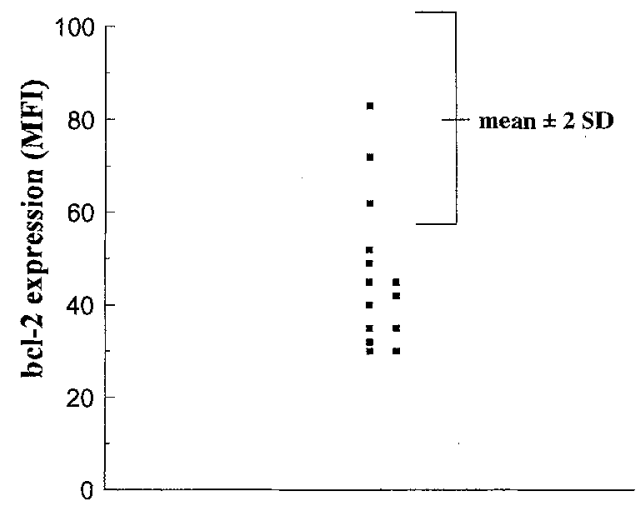

Fig. 1. Mean fluorescence intensity (MFI) of bcl-2 expression in $\mathrm{CD}_{3}{ }^{+}$cells in the newly-diagnosed IDDM patients $(\square)$ with respect to the mean values $\pm 2 \mathrm{SD}$ in the normal population. A significant difference was found between the normal subjects and the newly-diagnosed IDDM patients $(p<0.001)$

er in B than T cells (MFI difference $12 \pm 4.2$ channels).

When we analysed the group of newly-diagnosed IDDM patients, their T cells expressed lower levels of bcl-2 (46.8 \pm 15.4$)$ than those of control subjects $(p<0.001)$ (Fig. 1). Patients with IDDM of long duration showed an intermediate level of bcl-2 $(63.4 \pm 6.4)$ with respect to control subjects and newly-diagnosed patients (data not shown).

Figure 2 shows the different levels of MFI in one control subject and in one patient with IDDM. The dramatic difference is apparent and this is particularly evident when an overlay histogram examined on the same day with an identical setting of the flowcytometry analysis is considered. No difference in MFI of B cells was detected between control subjects and IDDM patients ( $82 \pm 9.8$ and $79.1 \pm 10.5$, respectively; $p=\mathrm{NS}$ ) and the other groups studied (data not shown).

Figure 3 shows the percentage levels of bcl-2 expression in CD45R0 ${ }^{+}$memory $\mathrm{CD}^{+}{ }^{+} \mathrm{T}$-lymphocytes. $\mathrm{Bcl}-2$ levels were significantly lower in newly-diagnosed IDDM patients with respect to normal subjects $(p<0.001)$.

High levels of spontaneous apoptosis are found in $C D 3^{+}$cells from IDDM patients during the 24-72-h 


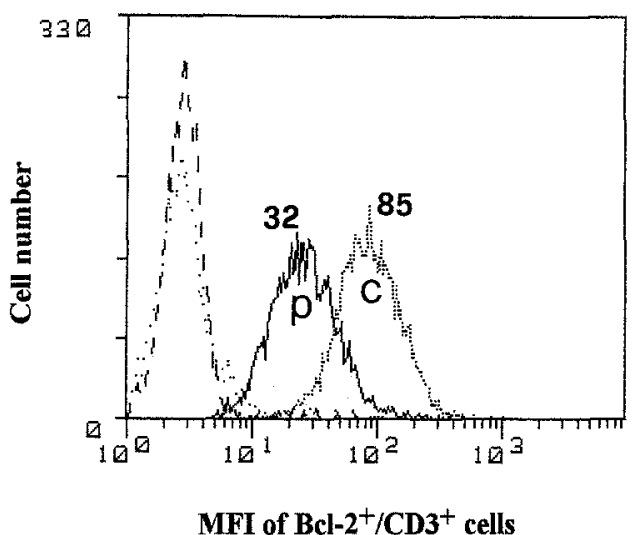

Fig. 2. Expression of bcl-2 in human $\mathrm{CD}^{+}$from one normal subject (C) and one newly-diagnosed IDDM patient (P). Histograms show negative control staining on the left, while MFI of $\mathrm{CD}^{+}$cells is indicated on the right. Numbers indicate MFI values. Identical setting of the flow-cytometry analysis was considered

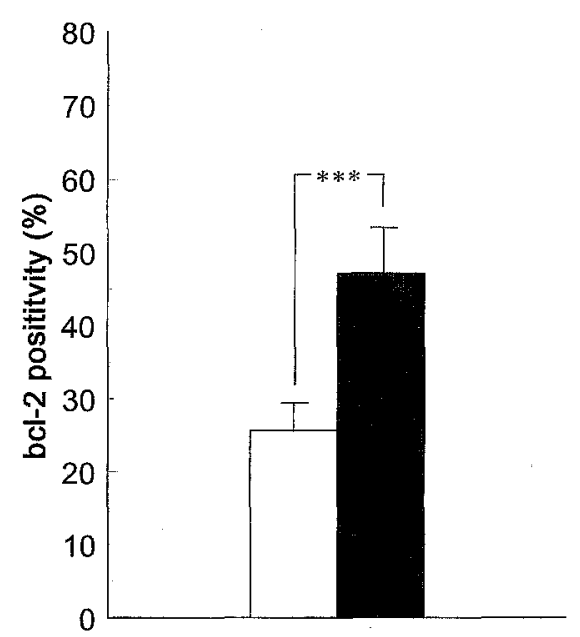

Fig. 3. Percentage levels of bcl- 2 in $\mathrm{CD} 4^{+} \mathrm{CD} 45 \mathrm{R} 0^{+}$lymphocytes in newly-diagnosed IDDM patients $(\square)$ and control subjects (蹗). Bars represent mean values \pm SD. $p<0.001$ for differences between the two groups

culture period. Flow cytometry analysis of PI-stained nuclei was performed on parallel cell cultures from control subjects and newly-diagnosed IDDM patients. For the whole duration of culture, higher levels of spontaneous apoptotic cells were found in the diabetic cohort than in control subjects $(p<0.02-0.001)$ (Fig. 4).

PI-stained nuclei from parallel cultures of $T$ cells in control subjects revealed a typical diploid DNA peak and a minor hypodiploid peak (Fig. 5, left panels); $\mathrm{T}$ cells from IDDM patients showed an impressive enhancement of the hypodiploid DNA peak (Fig. 5, right panels) during the $48-72 \mathrm{~h}$ period of observation.
C. Giordano et al.: Bcl-2 and spontaneous apoptosis in IDDM

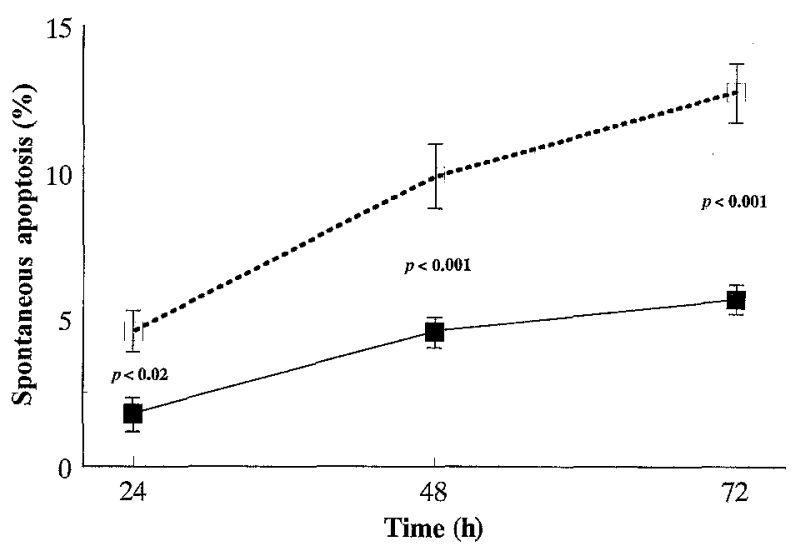

Fig.4. Mean values of percent DNA spontaneous fragmentation in newly-diagnosed IDDM patients (.. $\square \ldots)$ and in control subjects $\left(-{ }^{-}\right)$during the time course experiments. The mean values $\pm \mathrm{SD}$ examined are indicated

\section{Discussion}

Apoptosis is an important feature during embryonic or postnatal development. In the thymus, antigen receptor stimulation induces apoptosis and this is the mechanism believed to be responsible for clonal deletion of autoreactive $\mathrm{T}$ cells [23]. Bcl-2 has a well-established role in the regulation of cell survival associated with the selection and/or deletion of autoreactive cells in lymphoid organs. The loss of bcl-2 is linked to a short life span whereas the upregulation of this protein results in the relatively longer survival of immune cell types. Bcl-2 has been shown to block apoptosis [6].

To test the hypothesis that the hyporesponsiveness of peripheral $T$ cells we have reported in IDDM patients is at least partially due to increased spontaneous apoptosis of $\mathrm{T}$ cells, we directly evaluated spontaneous apoptosis and investigated its regulation by measuring bcl-2 expression in CD3-positive peripheral $\mathrm{T}$ cells from patients who had recently developed IDDM. Our findings show that bcl-2 expression is drastically reduced on the patients' $T$ cells whereas normal expression is found on their B lymphocytes. Thus, this is a T-cell-specific deficit. Furthermore, we have demonstrated that $T$ cells from newly-diagnosed IDDM patients are characterised by high levels of spontaneous apoptosis. As one would predict from the available knowledge on bcl- 2 function, the reduced bcl-2 expression we observed is associated with an increased level of spontaneous apoptosis in $T$ cells from IDDM patients in vitro. These findings are consistent with the hypothesis that reduced bcl-2 levels may lead to increased apoptosis of antigenprimed $T$ cells in the peripheral blood. As a hypothetical consequence, islet-specific activated T-cells could be deleted from the periphery, causing the in vitro deficit of T-cell activation [10-12, 24]. However, the fact that diabetic patients transplanted with iso- 

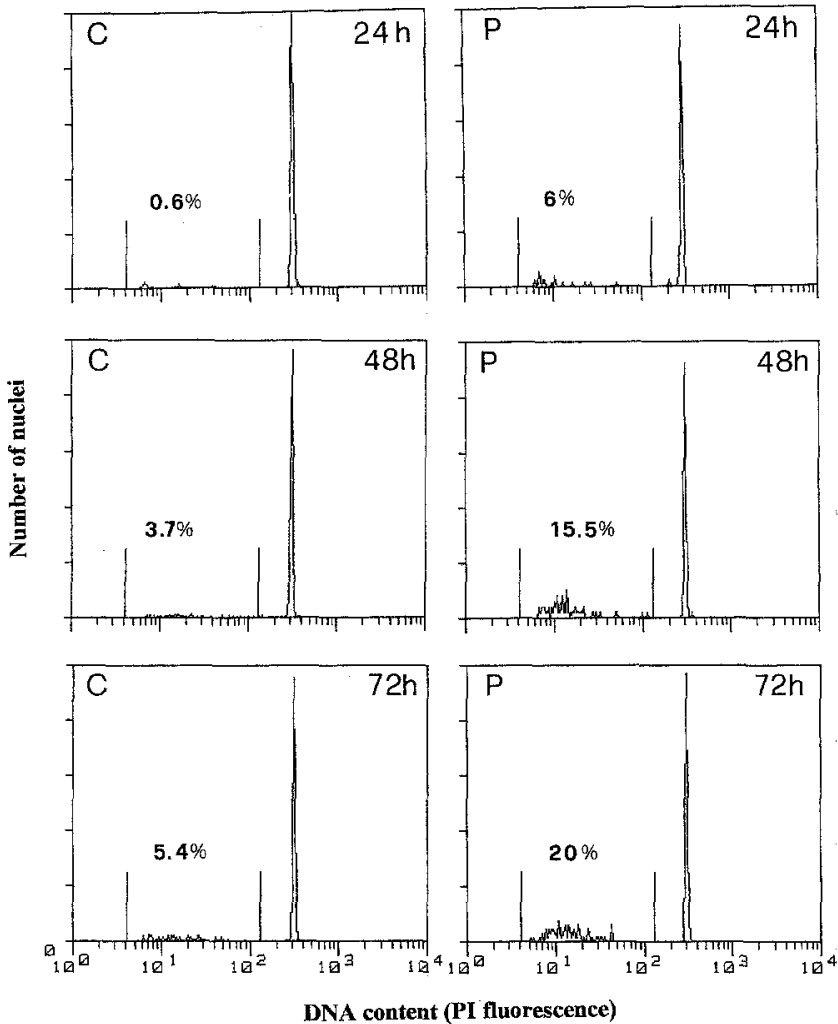

Fig.5. DNA fluorescence flow cytometric profiles of PIstained lymphocytes after 24-, 48- and 72-h incubation in medium alone. DNA histograms (log scale) after direct staining with hypotonic PI-fluorochrome solution. Left panels show values exhibited by one representative control subject; right panels indicate values found in one representative newly-diagnosed IDDM patient. Numbers indicate their relative apoptotic levels

grafts still reject them would indicate that islet reactive cells have not been fully deleted [25]. Whether the deficient expression of bcl-2 is an acquired defect or an inherited trait is at present not known. However, recent studies have shown that bcl-2 down-regulation is associated with the development of CD45RO cells after activation, and that bcl-2$\mathrm{CD}_{45 \mathrm{RO}^{+}}$include a subset of both CD4 and CD8 lymphoblasts found in infections with Epstein-Barr and VZV viruses [26]. Elevated percentage levels of $\mathrm{CD}_{45 \mathrm{RO}^{+}}$lymphocytes were found in diabetes-protected twins, whereas their percentages were significantly reduced in pre-diabetic twins [27]. The expansion of $\mathrm{CD} 45 \mathrm{RA}^{+} \mathrm{RO}^{+}$cells in pre-diabetic twins in association with a decrease in $\mathrm{CD} 45 \mathrm{RO}^{+}$cells has suggested that pre-diabetic twins have either a defect in T-cell maturation or an increased clearance of $\mathrm{CD} 45 \mathrm{RO}^{+}$memory cells. In this light, $\mathrm{CD} 4^{+}$ $\mathrm{CD} 45 \mathrm{RO}^{+} \mathrm{T}$ cells expressing low bcl-2, as found in the present study, might be those cells targeted by apoptosis. These findings would suggest that bcl-2 down-regulation and the consequent increase in apoptotic activity we found in IDDM may be due to environmental factors. This hypothesis is also supported by a recent study which provided clear evidence for the involvement of a superantigen as the priming antigen of islet-specific autoreactive $\mathrm{T}$ cells isolated from the pancreases of children who died at the time of IDDM onset [18].

In conclusion, IDDM is characterised by decreased bcl-2 expression and increased apoptosis of peripheral $\mathrm{T}$ cells. These abnormalities may represent the consequence of a viral infection, and increased apoptotic activity would result as a mechanism to eliminate $\mathrm{T}$ cells exposed to the viral agent. Further investigation is necessary to elucidate how these mechanisms relate to the pathogenesis of IDDM.

Acknowledgements. This work has been partially supported by CNR P.F. "Invecchiamento"- grant No 93. 00386.PF40, to A. Galluzzo; and by 40\% MURST 1992 Project "Fisiopatologia del Diabete, pancreas endocrino e correlazioni endocrino-metaboliche" - Comitato 06, to A. Galluzzo. We are indebted to Dr. A. Pugliese (Diabetes Research Institute, Miami, Fla., USA) for help with the manuscript preparation.

\section{References}

1. Krammer PH, Behrmann I, Daniel P, Dhein J, Debatin KM (1994) Regulation of apoptosis in the immune system. Curr Opin Immunol 6: 279-289

2. Lee S, Christakos S, Small MB (1993) Apoptosis and signal transduction: clues to a molecular mechanism. Curr Opin Cell Biol 5: 286-291

3. Schwartz LM, Osborne BA (1993) Programmed cell death, apoptosis and killer genes. Immunol Today 14: 582-590

4. Jenkinson EJ, Kingston R, Smith CA, Williams GT, Owen JJ (1989) Antigen-induced apoptosis in developing T-cells: a mechanism for negative selection of the $\mathbf{T}$ cell receptor repertoire. Eur J Immunol 19: 2175-2177

5. Cohen JJ (1993) Apoptosis. Immunol Today 14: 126-130

6. Williams GT, Smith CA (1993) Molecular regulation of apoptosis: genetic controls and cell death. Cell 74: 777-779

7. Gratiot-Deans J, Ding L, Turka LA, Nunez G (1993) Bcl-2 proto-oncogene expression during human T cell development. J Immunol 151: 83-91

8. Castano L, Eisenbarth GS (1990) Type I diabetes: a chronic autoimmune disease of human, mouse, and rat. Ann Rev Immunol 8: 647-679

9. Rossini AA, Handler ES, Greiner DL, Mordes JP (1991) Personal view. Insulin dependent diabetes mellitus hypothesis of autoimmunity. Autoimmunity 8: 221-235

10. Giordano C, De Maria R, Todaro M et al. (1993) Study of $\mathrm{T}$-cell activation in type I diabetic patients and pre-type I diabetic subjects by cytometric analysis: antigen expression defect in vitro. J Clin Immunol 13: 68-78

11. Giordano C, Pantò F, Caruso C et al. (1989) The interleukin-2 and soluble interleukin-2 receptor secretion defect "in vitro" in newly-diagnosed type I diabetic patients. Diabetes 38: $310-315$

12. De Maria R, Todaro M, Stassi G et al. (1994) Defective T cell receptor/CD3 complex signaling in human type I diabetes. Eur J Immunol 24: 999-1002

13. Atkinson MA, Kaufman DL, Campbell L et al. (1992) Response of peripheral-blood mononuclear cells to glutamate decarboxylase in insulin dependent diabetes. Lancet 339: $458-459$ 
14. Kaufman DL, Clare-Salzier M, Tian J et al. (1993) Spontaneous loss of T-cell tolerance to glutamic acid decarboxylase in murine insulin-dependent diabetes. Nature 366: 6972

15. Tisch R, Yang X-D, Singer SM, Liblau RS, Fugger L, McDevitt HO (1993) Immune response to glutamic acid decarboxylase correlates with insulitis in non-obese diabetic mice. Nature 366: 72-75

16. Roep BO, Arden SD, de Vries RRP, Hutton JC (1990) Tcell clones from a type-1 diabetic patient respond to insulin secretory granule proteins. Nature 345: 632-634

17. Elias D, Reshef T, Birk OS, Van Der Zee R, Walker M, Cohen IR (1991) Vaccination against autoimmune mouse diabetes with a T-cell epitope of the human $65 \mathrm{kDa}$ heat shock protein. Proc Natl Acad Sci USA 88: 3088-3091

18. Conrad B, Weldmann E, Trucco G et al. (1994) Evidence for a superantigen involvement in insulin-dependent diabetes mellitus aetiology. Nature 371: 351-354

19. National Diabetes Data Group (1979) Classification and diagnosis of diabetes mellitus and other categories of glucose intolerance. Diabetes 28: 1039-1057

20. Ad Hoc Expert Committee (1990) Position statement. Prevention of type I diabetes mellitus. Diabetes Care 13: 10261027

21. Schimd I, Uittembogaart HCH, Giorgi JV (1991) A gentle fixation and permeabilization method for combined cell surface and intracellular staining with improved precision DNA quantification. Cytometry 12: 279-285

22. Nicoletti I, Migliorati G, Pagliacci MC, Grignani F, Riccardi C (1991) A rapid and simple method for measuring thymocyte apoptosis by propidium iodide staining and flow cytometry. J Immunol Meth 139: 271-279

23. Hueber A-O, Raposo G, Pierres M, He H-T (1994) Thy-1 triggers mouse thymocyte apoptosis through a bcl-2-resistant mechanism. J Exp Med 179: 786-796

24. Giordano C (1992) T cell cloning in human type I diabetes. Diab Metab Rev 8: 39-51

25. Sibley RK, Sutherland DER, Goetz F, Michael AF (1985) Recurrence of diabetes mellitus in the pancreas iso- and allo-graft. A light and electron microscopic and immunohistochemical analysis of four cases. Lab Invest 53: 132-144

26. Akbar AN, Borthwick N, Salmon M et al. (1993) The significance of low bcl-2 expression by CD45RO T-cells in normal individuals and patients with acute viral infections. The role of apoptosis in T cell memory. J Exp Med 178: $427-438$

27. Peakman M, Alviggi L, Hussain MJ et al. (1994). Increased expression of T-cell markers of immunological memory associated with protection from type I diabetes. A study of identical twins. Diabetes 43: 712-717 